\title{
Câncer e Masculinidades: Sentidos Atribuídos ao Adoecimento e ao Tratamento Oncológico
}

\author{
Celina Maria Modena ${ }^{1}$ \\ Centro de Pesquisas René Rachou da Fundação Oswaldo Cruz, Belo Horizonte, \\ Minas Gerais, Brasil \\ Alberto Mesaque Martins \\ Faculdade de Filosofia e Ciências Humanas da Universidade Federal de Minas Gerais, \\ Belo Horizonte, Minas Gerais, Brasil \\ Andrea Pereira Gazzinelli \\ Instituto Mário Penna, Belo Horizonte, Minas Gerais, Brasil \\ Suellen Santos Lima de Almeida \\ Virginia Torres Schall \\ Centro de Pesquisas René Rachou da Fundação Oswaldo Cruz, Belo Horizonte, \\ Minas Gerais, Brasil
}

\begin{abstract}
Resumo
Apesar do crescente investimento na implantação de políticas públicas e programas de saúde voltados para a prevenção e diagnóstico precoce, o câncer ainda apresenta-se como uma das principais causas de morte em todo o mundo, com maior letalidade entre o público masculino. Na perspectiva da Pesquisa Qualitativa e ancorado nos pressupostos das Teorias de Gênero, este estudo teve como objetivo compreender as sentidos que os homens atribuem ao processo de adoecimento por câncer e ao tratamento oncológico. Foram entrevistados 16 pacientes, com diferentes tipos de neoplasias, internados em um hospital público, referência em oncologia, na cidade de Belo Horizonte - MG. Os resultados apontam para implicações do processo de socialização e construção da identidade masculina na maneira como os homens vivenciam o adoecimento e se vinculam às práticas de cuidado. A nova condição e as limitações impostas pela enfermidade e a rotina assistencial não-familiar, mostram-se incoerentes com a posição socialmente atribuída aos homens e contrárias aos padrões estabelecidos pelo modelo de masculinidade hegemônica, contribuindo para sentimentos de medo, tristeza e angústia. A necessidade de afastamento das atividades laborais e os reflexos do tratamento no exercício da sexualidade foram destacados pelos participantes, contribuindo para a sensação de redução e perda da masculinidade. Observa-se a necessidade do desenvolvimento de ações em saúde que considerem a dimensão de gênero, favorecendo assim o reconhecimento das necessidades de saúde específicas e as singularidades do público masculino.
\end{abstract}

Palavras-chave: Neoplasias, saúde do homem, gênero e saúde, Psicologia Social.

Endereço para correspondência: Escola de Enfermagem, Av. Alfredo Balena, 190, Sala 510, Santa Efigênia, Belo Horizonte, MG, Brasil 30130-100. E-mail: celinamodena@ufmg.br, albertomesaque@yahoo.com.br, deiagazzi@yahoo.com.br, almeidasuellen@ig.com.bre vtschall@cpqrr.fiocruz.br Financiamento: Trabalho financiado pela Fundação de Amparo à Pesquisa do Estado de Minas Gerais (FAPEMIG). 


\title{
Cancer and Masculinities: Meanings Attributed to Illness and to Oncology Treatment
}

\begin{abstract}
From the perspective of Qualitative Research and anchored on the assumptions Gender's Theories, this study aimed to understand the meanings that men attribute to the illness process of cancer and oncologic treatment. We interviewed 16 patients with different types of cancer, admitted to a public hospital, oncology reference, in the city of Belo Horizonte - MG. The results point to implications of the socialization process and the construction of masculine identity in the way that men experience the illness and are linked to the practices of care. The new condition and the limitations imposed by illness and routine care unfamiliar, appear incoherent with the position social attributed to men and contrary to the standards established by the model of hegemonic masculinity, contributing to feelings of fear, sadness and distress. The necessity of depart of labor activities and the reflections of treatment in the exercise of sexuality were highlighted by participants, contributing to the sense of reduction and loss of masculinity. Observes the need of developing of public health efforts to consider the gender dimension, favoring the recognition of specific health needs and singularities of the male audience.
\end{abstract}

Keywords: Neoplasms, men's health, gender y salud, Social Psychologist.

\section{Câncer y Masculinidades: Sentidos Atribuidos a la Enfermedad y a el Tratamiento Oncológico}

\section{Resumen}

En vista de la investigación cualitativa y anclado en las Teorías de Género, este estudio tuvo como objetivo comprender los sentidos que los hombres atribuyen al proceso de la enfermedad del cáncer y a el tratamiento oncológico. Entrevistamos a 16 pacientes con diferentes tipos de cáncer, admitidos en un hospital público de referencia en oncología, en la ciudad de Belo Horizonte - MG. Los resultados apuntan a las implicaciones del proceso de socialización y la construcción de la identidad masculina en cómo los hombres experimentan la enfermedad y se vinculan a las prácticas de cuidado. La nueva condición y las limitaciones impuestas por la enfermedad y la rutina de cuidado familiar, parecen coincidir con la posición socialmente asignados a los hombres y las contrarias a las normas establecidas por el modelo de masculinidad hegemónica, lo que contribuye a los sentimientos de miedo, tristeza y angustia. La necesidad de apartamiento de las actividades laborales y los reflejos de lo tratamiento en el ejercicio de la sexualidad fueron destacados por los participantes, lo que contribuye a la sensación de reducción y pérdida de la masculinidad. Se observa la necesidad de desarrollo de actividades de salud públicas a considerar la dimensión de género, favoreciendo el reconocimiento de las necesidades de salud específicas y singularidades del público masculino.

Palabras clave: Neoplasias, salud del hombre, género y salud, Psicología Social.

Apesar do crescente investimento na implantação de políticas públicas e programas de saúde voltados para a prevenção e diagnóstico precoce, o câncer ainda apresenta-se como uma das principais causas de morte em todo o mundo, configurando-se como a segunda principal Doença Crônica Não Transmissível - DCNT (Institu- to Nacional do Câncer [INCA], 2011). Segundo a Organização Mundial da Saúde (OMS), para o ano de 2030 são esperados 27 milhões de novos casos de câncer, 17 milhões de mortes e cerca de 75 milhões de pessoas convivendo, anualmente, com algum tipo de neoplasia. No Brasil, as estimativas para o biênio 2012-2013 apontam para 
a ocorrência de cerca de 518.510 novos casos anuais da doença, sendo 257.870 entre a população masculina (INCA, 2011).

Estudos destacam a necessidade de se considerar as implicações de gênero na configuração do quadro de morbimortalidade por câncer (Martins, Gazzinelli, Almeida, \& Modena, 2012; Xavier, Ataide, Pereira, \& Nascimento, 2010). Excetuando-se as neoplasias específicas de cada sexo, observa-se uma maior letalidade desta doença entre o público masculino (INCA, 2011; White, Thomson, Forman, \& Meryn, 2010). Sem desconsiderar a importância dos fatores biológicos, observa-se a necessidade de reflexão acerca dos aspectos sócio-culturais que permeiam a manutenção deste cenário (White et al., 2010).

Ainda hoje, nas culturas ocidentais, sobretudo a latinoamericana, "ser um homem de verdade" tem significado, na maior parte das vezes, optar por comportamentos que reforçam os estereótipos de força, coragem e determinação, contribuindo para que os homens coloquem em risco sua própria saúde e a daqueles que estão ao seu redor (Gomes, 2008). Em uma sociedade marcada pelas desigualdades de gênero, as ações de autocuidado trariam consigo um caráter de fragilidade, socialmente atribuído à figura das mulheres (Lago \& Muller, 2010). Soma-se ainda a maneira como os serviços de saúde são pensados e estruturados, caracterizados pela maior presença das mulheres, seja como trabalhadoras ou usuárias e, também, por uma maior oferta de ações assistenciais direcionadas ao público materno-infantil (Medrado, Lyra, Azevedo, Granja, \& Vieria, 2009; Schraiber et al., 2010).

Buscando construir ações estratégicas que contribuam para a promoção da saúde e redução da morbimortalidade masculina, no ano de 2009, foi instituída no Brasil a Política Nacional de Atenção Integral à Saúde do Homem (PNAISH; Mistério da Saúde, 2009). Tendo em vista o crescimento do número de novos casos de câncer entre a população masculina brasileira e a recorrente dificuldade de mobilização desse público para as ações de prevenção e diagnóstico precoce, a PNAISH vem incentivando a construção de um novo olhar sobre os homens, buscando compreender os aspectos simbólicos, socioculturais e organizacionais que interferem na maneira como exercitam o cuidado da saúde (Mistério da Saúde, 2009).

Por outro lado, no que se refere à literatura acadêmico-científica brasileira, ainda persiste um maior número de estudos centrados no adoecimento das mulheres e crianças com câncer, revelando assim a necessidade de estudos que considerem as especificidades do público masculino frente ao adoecimento por câncer e tratamento oncológico (Martins et al., 2013). Nesse sentido, este estudo teve como objetivo compreender os sentidos que os homens atribuem ao processo de adoecimento por câncer e ao tratamento oncológico.

\section{Método}

O estudo foi realizado na perspectiva da Pesquisa Qualitativa (Flick, 2009) tendo em vista o seu potencial de subsidiar a compreensão de vivências, experiências, sentidos, crenças e representações, valorizando diferentes perspectivas e considerando aspectos biopsicossociais, sobretudo, a dimensão sócio-histórica e política na qual os sujeitos existem.

O referencial teórico que orientou a pesquisa foram as Teorias de Gênero (Scott, 2005), em uma perspectiva relacional, especialmente os estudos voltados para a compreensão do processo de construção das masculinidades e suas implicações nos processos de saúde/adoecimento/cuidado (Gomes, 2008). Nessa perspectiva, gênero é tomado como uma categoria socio-histórica e política, configurando-se como um importante dispositivo analítico acerca do processo de transformação das diferenças sexuais, em instrumentos de desigualdades sociais e dominação.

Segundo Scott (2005), gênero refere-se a "um elemento constitutivo de relações sociais baseadas nas diferenças percebidas entre os sexos e . . uma forma primária de dar significado às relações de poder" (p. 86). Desse modo, o reconhecimento das diferenças sexuais abre espaço para a construção de estereótipos e delimita aos sujeitos lugares hierarquicamente distintos na tessitura social. 
Conforme destacam Machin et al. (2011) as concepções de gênero encontram-se inscritas no processo de socialização e construção da identidade de homens e mulheres, sendo portanto um elemento constituinte dos sujeitos, orientando assim os seus modos de pensar, sentir e agir em toda a vida social. Portanto, mais do que um comportamento natural o distanciamento dos homens dos serviços de saúde encontra-se intimamente relacionado aos modos de produção da existência e a uma sociedade alicerçado no processo de divisão sexual do cuidado (Lago \& Muller, 2010).

No campo da Saúde Coletiva tais concepções incidem na maneira como os sujeitos se vinculam aos serviços de saúde e nos modos como exercitam as práticas de cuidado (Gomes, 2008). No contexto institucional, as desigualdades de gênero contribuem para a constituição dos públicos beneficiários das ações ofertadas (Schraiber et al., 2010). Nesse sentido, constata-se no cenário brasileiro o reconhecimento das mulheres como sujeitos das políticas de saúde e a dificuldade de se inserir a população masculina nas propostas assistenciais, reforçando a suposição de que as mulheres estariam relacionadas ao cuidado da mesma forma que os homens estariam voltados para o risco e o não-cuidado, de forma pouco crítica e a-histórica (Lago \& Muller, 2010).

Para construção dos dados, foram realizadas entrevistas narrativas episódicas, que segundo Flick (2009) concentram-se na compreensão dos relatos dos sujeitos acerca de fatos, episódios e acontecimentos que se mostram relevantes para a compreensão do fenômeno estudado. Nesse sentido, foram entrevistados homens que receberam diferentes diagnósticos de câncer e que realizam tratamento oncológico em um hospital público beneficente, referência em oncologia, localizado na cidade de Belo Horizonte - Minas Gerais. Trata-se de uma instituição credenciada ao Sistema Único de Saúde (SUS) que recebe pacientes da capital e do interior do estado, sobretudo aqueles advindos de famílias de baixa renda.

Os participantes foram selecionados a partir dos seguintes critérios de intencionalidade: ter idade igual ou superior a 18 anos, ter sido diagnosticado com câncer, estar em condições clínicas para a entrevista e, aceitar ao convite de participação. O número de entrevistados foi determinado a partir dos critérios de saturação do discurso proposto por Flick (2009) onde o pesquisador suspende a inclusão de novos participantes quando as narrativas coletadas passam a apresentar redundância ou repetição.

Participaram do estudo 16 homens, com idade média de 62 anos, diagnosticados com diferentes tipos de neoplasias. Em sua maior parte, são casados, possuem baixa escolaridade, tendo cursado até o $5^{\circ}$ ano do Ensino Fundamental e pertencem às camadas populares, estando em maioria aposentados. Quanto ao tipo de câncer, predominaram pacientes diagnosticados com neoplasia maligna da próstata e neoplasia do cólon com lesão invasiva, corroborando com levantamentos epidemiológicos que apontam para maior incidência destes tipos de cânceres entre a população masculina brasileira, sobretudo, os homens com idade superior aos 40 anos (INCA, 2011).

As entrevistas estiveram alicerçadas nas narrativas acerca do processo de descoberta da doença; nas mudanças ocorridas durante o tratamento oncológico e nos sentidos atribuídos ao adoecimento e tratamento por câncer. As mesmas duraram em média 30 minutos, foram gravadas, transcritas e analisadas na perspectiva da Análise de Conteúdo (Bardin, 1976). Nesse sentido, foi realizada uma leitura exaustiva do material transcrito, possibilitando assim a identificação de categorias temáticas e unidades de significado que subsidiaram a interpretação dos dados e a construção dos resultados (Bardin, 1976).

O projeto foi submetido e aprovado pelo Comitê de Ética em Pesquisa do Centro de Pesquisa René Rachou, da Fundação Oswaldo Cruz (CPqRR - FIOCRUZ) - MG pelo parecer $n^{\circ}$ 13/2010, protocolo 03/2010 em cumprimento da Resolução 196/96 do Conselho Nacional de Saúde. Os entrevistados foram informados sobre os objetivos da pesquisa, da confidencialidade das informações e assinaram o Termo de Consentimento Livre e Esclarecido. Visando garantir o 
anonimato dos entrevistados, seus nomes foram substituídos pela letra E, indicando "entrevistado", seguida do respectivo número de identificação: E1, E2, E3, etc.

\section{Resultados e Discussão}

Após análise dos dados, os resultados foram sistematizados nas seguintes categorias temáticas: sentidos atribuídos pelos homens ao adoecimento por câncer e tratamento oncológico e; práticas de cuidado e vivências do tratamento.

\section{Sentidos Atribuídos pelos Homens ao Adoecimento por Câncer e Tratamento Oncológico}

O discurso dos entrevistados revela que os homens representam o câncer como uma doença grave, complexa, incurável e, fortemente associada à figura da morte. Resultados semelhantes vêm sendo identificados na literatura científica, evidenciando um processo socio-histórico e cultural de construção dos sentidos e significados atribuídos por diferentes grupos e sujeitos a esta enfermidade (Cayless, Forbat, Illingworth, Hubbard, \& Kearney, 2010; Oliveira \& Gomes, 2008): "Câncer é um negócio que não tem cura! Eu penso assim. A gente tem que fazer um controle pro resto da vida!" (E14). "É um mal que infelizmente não tem cura! É um tumor que cria dentro da pessoa, que ele vai destruindo a pessoa por dentro até levar à morte!" (E13).

$\mathrm{O}$ crescimento da incidência e da mortalidade por câncer no decorrer dos séculos, somado ao desconhecimento da sua etiologia e ao uso de formas invasivas e ineficazes de tratamento podem ter favorecido a construção destas modos de conceber a enfermidade. Apesar dos avanços científicos e tecnológicos na prevenção, diagnóstico e tratamento da doença, ainda percebe-se que o câncer ainda é cercado por tabus, interdições e preconceitos, assumindo, muitas vezes, um caráter de castigo e maldição (Oliveira \& Gomes, 2008).

Os sentidos que os entrevistados atribuem ao câncer encontram-se alicerçados nas experiências prévias dos sujeitos, sobretudo nas vivências pessoais em relação a parentes e amigos que experienciam o adoecimento. Observa-se que, na maior parte dos casos, tais vivências familiares tiveram como desfecho o agravo da condição clínica e a morte, refletindo assim no modo como estes homens se posicionam frente ao câncer e ao tratamento oncológico: "Eu perdi o meu pai faz dois anos. Ele tava com câncer. . . Eu tive treze tios. Onze morreram de câncer, tanto homens como mulheres" (E16).

Eu perdi o meu pai com câncer de próstata! Tem dez anos! Inclusive, outro dia faleceu um cara naquele leito ali ó, e daqui eu tava vendo: foi igual meu pai, que eu acompanhei meu pai! Choca, mas... [chora] o quê que posso fazer? (E1)

Alguns dos entrevistados chamam a atenção para a dificuldade ou mesmo a impossibilidade de se conversar sobre esta enfermidade, de modo que a palavra "câncer" não pode ser sequer pronunciada. Este fato parece estar pautado na tentativa de afastar do discurso as implicações do diagnóstico de câncer: "Câncer é uma palavra que não pode nem ser falada. Antigamente não podia nem falar a palavra!" (E13). "Eu não falo 'eu tenho'. Não falo! Porque se tiver uma rapa [resto] eu não quero! Eu falo: 'eu tive um câncer de laringe!" (E1).

A representação negativa e estigmatizante do câncer e o pavor da possibilidade de contágio, que permeia o imaginário social, encontram-se presentes no campo da linguagem. Ao trazerem para o discurso a temática do câncer, observa-se um fenômeno de personificação da enfermidade. Assim, a doença passa a ser representada pelos entrevistados a partir de características humanas, deixando de ser considerada apenas como uma entidade biológica, assumindo um lugar simbólico permeado por sentidos e significados socioculturais. No discurso destes homens, o câncer passa a ser caracterizado por atitudes, desejos e vontades próprias, predominando um movimento de destruição do sujeito adoecido: "Essa doença é perigosa e traiçoeira! . . Não bobeia, não facilita que o negócio é traiçoeiro! Não deixa ele te pegar não!" (E15). "Eu só sei que é uma doença que é complicada! . . Ela é muda, surda e cega! . . Ela não indica. Ela aparece. Ela não dá sinal de vida!" (E2). 
O recebimento do diagnóstico foi apontado pelos entrevistados como um momento impactante marcado por sentimentos de angústia, medo, tristeza e desespero. As narrativas dos entrevistados revelam que os sentidos atribuídos ao câncer se materializam em metáforas como "impacto", "choque", "pedrada" e ainda, na facticidade da "morte", destacando assim, o impacto agressivo e mutilador do diagnóstico na biografia destes sujeitos: "É um impacto terrivel! O chão acaba debaixo da gente! É um impacto assim, super desagradável!" (E15). "Nossa! Pra mim foi uma pedrada! . . Na hora eu debrucei em cima da cama e comecei a chorar! Fiquei desesperado! ... Vocêfica pensando que vai durar pouco, que vai deixar a família e tudo ai!!" (E14).

Ao deparar-se com o diagnóstico de uma doença crônica, como o câncer, os homens são levados a defrontar-se com suas fragilidades, limitações e necessidades de cuidados, até então, negligenciadas e comumente associadas ao âmbito do feminino. Tais vivências contribuem para a ideia de subtração ou perda da masculinidade, uma vez que esta se encontra pautada socialmente em padrões distintos daqueles impostos pelo adoecimento e tratamento oncológico. Nesse sentido, o diagnóstico de câncer coloca os homens em uma nova condição que se contrapõe aos modos como estes cotidianamente exercitam e vivenciam suas masculinidades.

Resultados semelhantes vêm sendo destacados na literatura revelando que o diagnóstico de câncer provoca uma ruptura na biografia dos homens, delimitando um período anterior e outro posterior à enfermidade (Martins et al., 2012; Xavier et al., 2010). Estudos apontam ainda para o fato de que ao se deparar com o adoecimento por câncer é recorrente que estes sujeitos experienciem sentimentos de vulnerabilidade, falta de controle, vitimização, perda da independência, redução da autonomia e sensação de perda da masculinidade (Cayless et al., 2010; Wall \& Kristjanson, 2004).

A partir da confirmação do diagnóstico de câncer o sujeito atravessa um processo de mudanças e transformações do seu cotidiano, tendo em vista as novas rotinas ou mesmo algumas limitações impostas pelo adoecimento e tratamen- to oncológico. Nesse sentido, novos contextos, situações e pessoas passam a fazer parte do seu dia a dia, exigindo modificações, adaptações ou interrupções nos projetos de vida (Mesquita, Moreira, \& Maliski, 2011).

Distantes das ações e serviços de saúde, os entrevistados foram repentinamente levados a conviver com um mundo pouco familiar e incoerente com seus planos de vida anteriores ao adoecimento exigindo assim a ressignificação dos modos de pensar, sentir e agir. Somam-se ainda as mudanças físicas propiciadas pela condição clínica e tratamento oncológico, geralmente traduzidas em emagrecimento ou ganho de peso, inchaço, alopécia, náuseas e vômitos, inapetência, dentre outros, incidindo assim na percepção corporal e na autoestima destes sujeitos: "A gente emagrece. Eu cheguei a emagrecer 24 quilos!" (E14).

Eu vou pra casa e tenho que sair com essa bolsa [de ostomia] pendurada aqui e ficar pelo menos 10 dias ou mais . . Eu agora não vou ser aquela pessoa que posso fazer aquilo que eu gosto de fazer, ou se posso fazer alguma coisinha, mas muito menos do que eu fazia! (E11)

Conforme destaca Jardim (1995), para além da sua dimensão orgânica, o corpo apresenta-se como um suporte de significados sociais e políticos, recebendo assim inscrições simbólicas que produzem modos específicos de viver e se colocar no mundo. Para esta autora, é no corpo que a masculinidade é vivenciada e materializada, sobretudo na representação do corpo ativo, forte, invulnerável e reprodutor, remetendo à imagem do "homem de ferro". Para Kelly (2009), as mudanças provocadas pelo adoecimento e tratamento oncológico contribuem para o sentimento dos homens de que seus corpos falharam na sustentação dos ideais e padrões estabelecidos pela masculinidade hegemônica.

Dentre as mudanças ocorridas, o impacto do câncer no desempenho sexual foi destacado pelos entrevistados, revelando tratar-se de uma transformação significativa e de difícil elaboração. Embora o próprio diagnóstico de câncer já incida na diminuição do desejo sexual (Kelly, 2009; Wall \& Kristjanson, 2004), os pacientes submetidos à prostatectomia relataram maiores 
implicações do tratamento em sua sexualidade que os homens diagnosticados com outros tipos de neoplasias. Estas singularidades podem ser compreendidas tendo em vista os próprios efeitos colaterais dos procedimentos cirúrgicos na próstata, contudo, não se restringem apenas aos mesmos, referindo-se também à dimensão psicossocial destes sujeitos: "A ereção eu não tenho mais. Depois da cirurgia não funciona mais não. Quando eu fiquei sabendo que tava câncer, o negócio não funciona mais não. Ficou assim mesmo, não dá sinal de vida!" (E16).

Eu já vi que muda totalmente. Você não é mais homem! . . Você não tem mais ereção, você não faz mais sexo. A sua mulher é viúva de homem vivo! Então é terrivel pra gente falar isso, mas é verdade! Mexeu nessa parte aí, acabou a sexualidade do homem! E acabou mesmo! Não é acabar pela metade não! Acaba por inteiro e de um modo terrivel! (E15)

Observa-se nestas narrativas a intrínseca relação atribuída entre a atividade sexual e o exercício das masculinidades, de maneira que, para estes homens, a redução da capacidade de ereção passa a ser percebida como uma subtração ou perda da masculinidade. Conforme ressalta Gomes (2008), no contexto brasileiro, ainda persiste a representação dos homens como seres sexualmente ativos e dominadores e constantemente a procura de uma parceira para o ato sexual, levando à construção da ideia de um corpo masculino que atenda estas demandas culturais. Deste modo, a capacidade de ereção e a contínua disponibilidade para a atividade sexual atuam como importantes signos que atestam a virilidade e a autenticidade da masculinidade frente ao grupo social.

Tratando-se dos pacientes submetidos a procedimentos cirúrgicos na próstata, um fato chama a atenção: a necessidade de assinatura do Termo de Consentimento Informado (TCI), proposto pela equipe médica. Segundo orientações da Sociedade Brasileira de Urologia (SBU), é necessário que as equipes de saúde orientem aos pacientes sobre os possíveis efeitos desses procedimentos como incontinência urinária, dificuldades de ereção, impotência sexual, dentre outras. Assim, após receber as devidas orienta- ções, o paciente deve atestar o seu consentimento por escrito, eximindo o profissional de futuros processos na justiça ou mesmo no Conselho Regional de Medicina (SBU, 2011).

Considerando-se a incipiente utilização dos consentimentos formais nos serviços de saúde brasileiros, ao ser solicitado, o TCI passa a ser percebido pelos pacientes como indicativo de ameaça à integridade física e moral, disparando sentimentos de angústia, suspeita e medo. Em outras palavras, se durante todo o tratamento não foi solicitado ao paciente seu consentimento formal, sua real necessidade passa a ser questionada, favorecendo o surgimento de fantasias e crenças que podem dificultar ou inviabilizar o tratamento oncológico: "Tive [que assinar], mas eu não entreguei pra eles [médicos]. Não me cobraram. O termo está comigo. . . . Ah, eu fiquei assim meio apreensivo. Se eles estão pedindo pra assinar é porque o negócio é perigoso né!" (E15).

Deve-se considera a complexidade que perpassa a utilização do TCI nos diferentes serviços de saúde. Bulla, Benincasa, Goldim e Francisconi (2003) ressaltam tratar-se de instrumentos padronizados que desconsideram a diversidade sociocultural e os diferentes níveis de compreensão da população atendida, exigindo assim, escolaridade alta e elevado índice cognitivo. No presente estudo, observa-se que a assinatura do TCI foi percebida pelos homens como uma escolha entre poucas alternativas, porém com implicações significativas que dizem respeito ao viver ou morrer. Nesse sentido, os entrevistados afirmam ter optado pela vida, ainda que isto se traduzisse em mudanças indesejadas e de difícil adaptação: "O doutor me explicou tudo direitinho. Mas eu vou fazer o que? Eu quero é viver! Então, poxa, essa parte morreu aqui! Agora minha vida continua!" (E15).

Isso ai é bem dificil pra gente! Mas eu aceitei numa boa, falei: a vida é mais importante! Já realizei muito prazer na vida, caso se vir agora uma coisa me atrapalhar, não tem problema! Eu tendo saúde pra mim, viver é mais importante! (E10)

Para Giostri (2003), o consentimento informado não deve ser reduzido à dimensão de protocolo formal, mas, deve ser compreendido 
como um processo pautado na escuta e no diálogo entre o paciente e o profissional de saúde. Nesse sentido, cria-se espaço para manifestação e esclarecimento de dúvidas, avaliação de outras possibilidades, conscientização sobre os possíveis riscos, resultando em acordo e participação no tratamento. Entretanto, no presente estudo, os entrevistados chamaram a atenção para a postura do médico durante o processo de aplicação do TCI, indicando a fragilidade do diálogo e a grande ênfase dada no medo e morte, por parte dos profissionais: "Ou assina ou então não faz a cirurgia! Então assinei. Se tem que fazer a gente tem que arriscar!" (E13).

Primeiro ele [médico] leu pra mim. Me explicou qual situação era. Ai ele falou: "Não! O senhor tem uma saída só! Se o senhor se interessar mais pela vida ou, senão, se abandonar e ficar ai igual uns ficam até a mingua, emagrecem, adoecem, vai morrendo aos pouquinhos". Ai eu falei: "não, eu prefiro viver uai"! Claro! (E10)

Outra dimensão significativa destacada pelos entrevistados refere-se às implicações da necessidade de afastamento das atividades laborais, tendo em vista as limitações físicas impostas pelo adoecimento e a rotina do tratamento oncológico. Deve-se considerar o importante papel que o trabalho ocupa na construção e reafirmação da identidade masculina, configurando-se como instituição social que possibilita aos homens assumir o lugar de provedor e responsável financeiro de si mesmo e de seus familiares, bem como uma posição de autoridade sobre suas mulheres e filhos (Gomes, 2008). Tratando-se do adoecimento por câncer ao serem afastados do trabalho ou, em alguns casos, aposentados por invalidez, esses sujeitos vivenciam uma mudança brusca e significativa no seu cotidiano, conforme indicam os entrevistados: "Nossa! Foi horrivel [deixar de trabalhar]! Foi pior que a doença! . . . A única coisa que me deixou contrariado foi isso!" (E3). "Eu gosto de trabalhar e agora, não sei . . . Depois de uma operação dessa, com certeza ele vai falar comigo que eu não posso trabalhar em serviço pesado e ai eu não vou ficar muito satisfeito!" (E11).

Se por um lado, o trabalho ocupa um importante papel na constituição da identidade mas- culina, constata-se sua ausência ou impedimento também implica em um processo de reconstrução dos significados atribuídos ao "ser homem". Os entrevistados apontam para o trabalho como um espaço de socialização que transcende à dimensão financeira e econômica. Somado ao suporte material, as atividades laborais proporcionam o sentimento de autonomia, confiança e ainda, conferem aos homens um reconhecimento social de seus esforços e dignidade: " $O$ trabalho ajuda muito, que ocupa a mente da gente, sabe, e evita até a dor" (E1).

Mas os bicos eu voltei a fazer só porque eu não suporto ficar a toa. Não foi por necessidade não, sabe. Eu não agüento ficar a toa! Então eu procurei muito serviço, bem maneiro, que eu trabalhasse o dia que eu quisesse, a hora que quisesse, para não criar um vinculo trabalhando. (E13)

Frente à impossibilidade de continuar trabalhando, estes homens vivenciam uma dupla exclusão: a primeira é marcada pelo adoecimento e suas implicações na vida cotidiana e, a segunda, ancora-se na perda da capacidade física de continuar exercendo as atividades laborais, sendo percebidos, então, como seres "improdutivos", "incapazes", ou como descrito nos atestados ocupacionais, "inválidos". Em uma sociedade onde cada vez mais se associa o masculino ao trabalho, à capacidade produtiva e de geração de recursos financeiros, receber este diagnóstico, implica também em uma crise de identidade, marcada por sentimentos de baixa autoestima, perda do significado da vida e rompimento com o grupo de iguais.

Quando você sai do trabalho são poucos que te procuram. Então você tem que viver muito pra você não ficar com ressentimento das pessoas. . . Mas um trabalhador ele já sai de lá cansado, os companheiros de trabalho, quando sai todo mundo a tarde, cada um vai pra sua casa... A turma não vai visitar a gente! (E1)

\section{O Cuidado com a Saúde e o Tratamento Oncológico}

O discurso dos entrevistados aponta para o distanciamento destes sujeitos dos serviços de saúde e revelam um histórico marcado pela 
fragilidade no cuidado de si e dificuldades de adesão às ações de prevenção e diagnóstico precoce. Na maior parte dos casos, o câncer só foi descoberto a partir de outros eventos traumáticos que demandaram a realização de exames diagnósticos. Estes dados corroboram com a literatura científica que revela o distanciamento da população masculina das ações de prevenção e promoção da saúde, procurando a assistência, predominantemente, em casos de acidentes e doença manifesta já em estado avançado de adoecimento (Medrado et al., 2009; Mistério da Saúde, 2009; White et al., 2010): "Eu comecei a ter retenção urinária. A gente é leigo no assunto né. Eu demorei a procurar o médico e quando procurei ele falou que eu vou ter que fazer uma redução de próstata que ela cresceu" (E2).

Eu tava na casa da minha irmã e eles fizeram uma feijoada lá caprichada e eu resolvi comer um pouquinho e agarrou na minha garganta. Eu tomei água por cima e não resolveu nada. Ai isso foi no sábado. Quando foi na segunda feira eu fiz uma endoscopia e acusou tudo, ai já comecei o tratamento. (E15)

O distanciamento dos homens dos serviços de saúde não deve ser tomado como algo naturalizado, mas compreendido a partir do processo de socialização e construção da identidade masculina, permeado pelas desigualdades de gênero (Lago \& Muller, 2010). Ao contrário das mulheres, os homens, deste a tenra infância, são pouco estimulados a perceber o seu próprio corpo e atentar-se às suas sensações, refletindo numa maior dificuldade no reconhecimento de sintomas, contribuindo para uma procura de assistência tardia, pontual e emergencial (Medrado et al., 2009; White et al., 2010;). Este distanciamento foi apontado pelos entrevistados: "Nunca gostei [de ir ao médico] . . . Sem estar doente, para olhar se tinha alguma coisa, não ia não" (E11).

Ah muito dificil o homem nessa parte! A mulher vai mais [aos serviços de saúde]. $O$ homem vai menos. O homem preocupa mais com o trabalho ... [Eu] não ia em médico nenhum! . . Quando eu tinha uma dor de cabeça tomava um remédio ... Só ia quando já tava passando mal. (E14)
Conforme destaca Braz (2005) a dimensão de gênero não produz apenas modos de vida, mas também diferentes modos de adoecimento e morte, sendo então uma importante categoria que permeia os serviços de saúde e as ações de cuidado. Nesse sentido, a maior familiaridade das mulheres com os serviços e profissionais de saúde parece contribuir para que estas apresentem maior disponibilidade e facilidade para adaptar-se às novas rotinas e modificações impostas pelo adoecimento.

Se por um lado, os serviços de saúde, sobretudo aqueles do âmbito da Atenção Primária, apresentam-se como algo familiar e de uso cotidiano para as mulheres, o mesmo não ocorre quando considerado o público masculino (Couto et al., 2010; Machin et al., 2011). O mesmo parece repetir, quando considerados os serviços especializados em oncologia. Os discursos dos homens entrevistados apontam que diante da rotina hospitalar, até então desconhecida ou pouco familiarizada, os mesmos vivenciaram sentimentos de insegurança e medo. Os procedimentos cirúrgicos foram destacados por eles como sendo um evento marcante que, dada o caráter de novidade e a incipiência de informações acerca dos mesmos, foi vivenciado como um momento de grande angústia: "Deu medo assim, quando eu cheguei lá na sala de cirurgia, eles ligando aqueles aparelhos em mim e conversando lá. Ai deu medo!" (E5).

Vim, não que eu gosto de vim . . Vim tremendo e suando frio! Suava, menino, suava mesmo. ... Quando entrei na sala [de cirurgia] a mulher me aplicou, me deu $5 \mathrm{ml}$ acho que de relaxante. Ela viu que eu tava muito tenso, foi lá e aumentou a dose! (E16)

De forma semelhante, a necessidade de internação foi percebida como um fator limitante da liberdade, contribuindo para sentimentos de perda do controle e redução da autonomia. A dificuldade de adaptação dos homens à rotina de tratamento oncológico vem sendo apontada em outros estudos, revelando que estes implicam em modos de vida incoerentes com aqueles estabelecidos pela masculinidade hegemônica (Cayless, 2010; Gannon, Guerra-Blanco, Patup, \& Abel, 2010; Mesquita et al., 2011). 
Embora os aspectos relacionados à socialização ocupem um importante papel no distanciamento das ações de cuidado, faz-se necessário refletir sobre as concepções dos profissionais de saúde sobre o atendimento dos homens e ainda, sobre a maneira como os serviços assistenciais são pensados e organizados. Conforme destacam Schraiber et al. (2010), os serviços de saúde ainda priorizam a escuta e compreensão das demandas do público materno-infantil, abrindo pouco espaço para o reconhecimento das necessidades da população masculina.

Somado ao silenciamento das questões de gênero, é recorrente que os serviços de saúde apresentem problemas estruturais e organizacionais, perceptíveis aos usuários que também podem configurar-se como barreiras que dificultam o acesso e a construção de vínculos com estes sujeitos (Couto et al., 2010; Machin et al., 2011). Dessa forma, a demora no atendimento, as deficiências no acolhimento, a ausência de estratégias que garantam a privacidade, assim como outros problemas institucionais, como a sobrecarga e a precariedade das condições de trabalho também devem ser considerados na análise do distanciamento dos homens dos serviços de saúde, evitando assim, culpabilizá-los pelo próprio adoecimento.

Outra dimensão apontada pelos entrevistados refere-se à dificuldade de comunicação com a equipe de saúde, sobretudo os médicos responsáveis pelo atendimento. Analisando o atendimento à saúde de homens, na perspectiva de usuários de quatro estados brasileiros, Gomes et al. (2011) chamam a atenção para a recorrente associação da boa assistência à qualidade da comunicação nos processos de cuidado. Para os autores, mais do que informações, a população masculina deseja um processo dialógico e horizontal no qual seja possível a expressão de dúvidas, medos e a compreensão mútua.

Ainda hoje, persistem nos serviços de saúde as práticas verticais de comunicação, pautadas na posição de autoridade da profissão e na representação dos sujeitos usuários como incapacitados e submissos às decisões da equipe (Schraiber et al., 2010). Nessa perspectiva as ações educativas mostram-se alicerçadas na transmissão e acúmulo de informações, quase sempre, permeadas pelo medo e figura da morte, gerando um impacto e pavor na população, sem, no entanto, favorecer a mobilização e engajamento dos sujeitos nas ações de cuidado. O discurso dos entrevistados aponta para as dificuldades na comunicação durante o tratamento oncológico.

Não, eu nunca conversei [com o médico]. A gente tem pouco acesso a eles.... Quando eu cheguei eu entreguei os exames a ele... Ele falou: "ó, isso aqui você tem que retirar a próstata" e depois não tinha tempo pra conversar com ele, que tava assim de gente pra falar com ele e dai pra cá eu não encontro o doutor X. Quando eu fui operado já era uma outra equipe ... Quando me levaram pro bloco, eu cheguei lá, tava as enfermeiras. As enfermeiras foram me preparando logo e então não tem tempo da gente dialogar e tal, perguntar, tirar algumas dúvidas. (E11)

\section{Considerações Finais}

As narrativas dos homens entrevistados revelam que o processo de saúde/adoecimento/cuidado deve ser compreendido a partir da análise do contexto sócio-histórico, político e cultural no qual os sujeitos existem. Desse modo, a experiência de adoecimento por câncer e tratamento oncológico passa a ser vivenciada e representada de forma articulada ao modo como os homens exercitam e significam as masculinidades no cotidiano.

A nova condição e as limitações impostas pela enfermidade e a rotina assistencial, mostram-se incoerentes com a posição socialmente atribuída aos homens e contrárias aos padrões estabelecidos pelo modelo de masculinidade hegemônica, explicitando marcas do processo de socialização e construção da identidade masculina. Assim, ao adentrar os serviços de saúde, os homens carregam consigo suas histórias, suas representações, seus sentidos e afetos, favorecendo assim um encontro com uma realidade até então pouco conhecida e não-familiar.

Entretanto, o distanciamento dos homens dos serviços de assistência, prevenção e diagnóstico precoce do câncer não se resumem apenas às dificuldades de vinculação oriundas do 
comportamento desta população. Os sentidos atribuídos ao câncer, construídos e compartilhados socialmente, bem como, a forma como os serviços de saúde são pensados e estruturados também podem ser considerados como importantes elementos que dificultam ou até mesmo inviabilizam o acesso e vinculação dos homens a estes espaços, merecendo ser incluídas na compreensão deste cenário.

Por fim, faz-se necessário investir no desenvolvimento de novos estudos que considerem diferentes facetas do complexo processo pelo qual os homens vivenciam o adoecimento por câncer e tratamento oncológico. Tal discussão poderá subsidiar o desenvolvimento de novas estratégias e ações de saúde que considerem homens e mulheres, como seres históricos, políticos e, portando, genderizados, rompendo com a perspectiva biomédica e reducionista que reduzem estes sujeitos à sua dimensão biológica e comportamental. Requer ainda iniciativas de formação dos profissionais de saúde e de programas informativos/educativos para a população masculina e famílias de modo a estimular processos de atenção á saúde para e pelos homens.

Mais do que a normatização e padronização dos processos assistenciais em saúde, esta mudança implicará em uma nova ética e um novo posicionamento frente aos usuários, respeitando e assegurando os princípios da equidade, universalidade e integralidade que sustentam o SUS.

\section{Referências}

Bardin, L. (1976). Análise de Conteúdo. São Paulo, SP: Martins Fontes.

Braz, M. (2005). A construção da subjetividade masculina e seu impacto sobre a saúde do homem: Reflexão bioética sobre justiça redistributiva. Ciência \& Saúde Coletiva, 10(1), 97-104.

Bulla, M. C., Benincasa, C. C., Goldim, J. R., \& Francisconi, C. F. M. (2003). O uso do termo de consentimento informado nas áreas assistenciais do Hospital das Clínicas de Porto Alegre. Revista AMRIGS, 47(2), 101-103.

Cayless, S., Forbat, L., Illingworth, N., Hubbard, G., \& Kearney, N. (2010). Men with prostate cancer over the first year of illness: Their experiences as biographical disruption. Support Care Cancer, 18(1), 11-19.
Couto, M. T., Pinheiro, T. F., Valença, O., Machin, R., Silva, G. S. N., Gomes, R., ...Figueiredo, W. S. (2010). O homem na atenção primária: Discutindo a (in)visibilidade a partir da perspectiva de gênero. Interface: Comunicação, Saúde \& Educação, 14(33), 257-270.

Flick, U. (2009). Introdução à pesquisa qualitativa (3. ed.). Porto Alegre, RS: Artmed.

Gannon, K., Guerra-Blanco, M., Patup, A., \& Abel, P. (2010). Re-construction masculinity following radical prostatectomy for prostate cancer. The Aging Male, 13(4), 258-264.

Giostri, H. T. (2003). Sobre o consentimento informado: Sua história, seu valor. Jornal Vascular Brasileiro, 2(3), 267-270.

Gomes, R. (2008). Sexualidade masculina: Gênero e saúde. Rio de Janeiro, RJ: Editora da Fundação Oswaldo Cruz.

Gomes, R., Scraiber, L. B., Couto, M. T., Valença, O., Silva, G. S. N., Figueiredo, W. S., ...Pinheiro, T. F. (2011). O atendimento à saúde de homens: Estudo qualitativo em quatro estados brasileiros. Physis Revista de Saúde Coletiva, 21(1), 113-128.

Instituto Nacional do Câncer. (2011). Estimativa 2012: Incidência do câncer no Brasil. Rio de Janeiro, RJ: Autor.

Jardim, D. F. (1995). Performances, reprodução e produção dos corpos masculinos. In O. F. Leal, Corpo e Significado: Ensaios de Antropologia Social (pp. 193-206). Porto Alegre, RS: Editora da Universidade Federal do Rio Grande do Sul.

Kelly, D. (2009). Changed men: The embodied impact of prostate cancer. Qualitative Health Research, 19(2), 151-163.

Lago, M. C. S., \& Muller, R. C. F. (2010). O sujeito universal do cuidado no SUS: Gênero, corpo e saúde nas falas de profissionais e usuários do Hospital Universitário - Florianópolis, Santa Catarina. In M. N. Strey, C. Nogueira, \& M. R. Azambuja, Gênero e Saúde: Diálogos ibero-brasileiros (pp. 279-302). Porto Alegre, RS: Editora da Pontifícia Universidade Católica do Rio Grande do Sul.

Machin, R., Couto, M. T., Silva, G. S. N., Schraiber, L. B., Gomes, R., Figueiredo, W. S., ...Pinheiro, T. F. (2011). Concepções de gênero, masculinidade e cuidados em saúde: Um estudo com profissionais de saúde da atenção primária. Ciência e Saúde Coletiva, 16(11), 4503-4512. 
Martins, A. M., Gazzinelli, A. P., Almeida, S. S. L., \& Modena, C. M. (2012). Concepções de psicólogos sobre o adoecimento de homens com câncer. Psicologia: Teoria e Prática, 14(2), 74-87.

Martins, A. M., Moraes, C. A. L., Ribeiro, R. B. N., Almeida, S. S. L., Schall, V. T., \& Modena, C. M. (2013). A produção científica brasileira sobre o câncer masculino. Revista Brasileira de Cancerologia, 59(1), 105-112.

Medrado, B., Lyra, J., Azevedo, M., Granja, E., \& Vieria, S. (2009). Princípios, diretrizes e recomendações para uma atenção integral aos homens na saúde. Recife, PE: Instituto PAPAI.

Mesquita, M. G. R., Moreira, M. C., \& Maliski, S. L. (2011). "But i'm (became) different". Cancer nursing, 34(2), 150-157.

Mistério da Saúde. (2009). Política Nacional de Atenção Integral à Saúde do Homem: Princípios e diretrizes. Brasília, DF: Autor.

Oliveira, A. P., \& Gomes, A. M. T. (2008). A estrutura representacional do câncer para os seus portadores: Desvelando seus sentidos e dimensões. Revista de Enfermagem da UERJ, 16(4), 525-531.

Schraiber, L. B., Figueiredo, W. S., Gomes, R., Couto, M. T., Pinheiro, T. F., Machin, R., ...Valença, O. A. (2010). Necessidades de saúde e masculinidades: Atenção primária no cuidado aos homens. Cadernos de Saúde Pública, 26(5), 961-
970.

Scott, J. (2005). Gênero: Uma categoria útil de análise histórica. Educação \& Realidade, 20(2), 71-99.

Sociedade Brasileira de Urologia. (2011). Modelos de Termos de Consentimentos Pós-Informados em Urologia. Recuperado em 20 de novembro, 2012, de http://www.sbu.org.br

Wall, D., \& Kristjanson, L. (2004). Men, culture and hegemonic masculinity: Understanding the experience of prostate cancer. Nursing Inquiry, 12(2), 87-97.

White, A. K., Thomson, C. S., Forman, D., \& Meryn, S. (2010). Men's health and the excess burden of cancer in men. European Urology Supplements, $9(1), 467-470$.

Xavier, A. T. F., Ataide, M. B. C., Pereira, F. G. F., \& Nascimento, V. D. (2010). Análise de gênero para o adoecer de câncer. Revista Brasileira Enfermagem, 63(6), 921-926.
Recebido: 28/03/201

$1^{a}$ revisão: $17 / 07 / 2013$

Aceite final: 23/07/2013 